\title{
Modification of porous polyethylene scaffolds for cell attachment and proliferation
}

This article was published in the following Dove Press journal:

International Journal of Nanomedicine

\author{
Poulomi Sengupta \\ Sachin S Surwase \\ Bhagavatula LV Prasad \\ Physical Chemistry Division, \\ CSIR-National Chemical Laboratory, \\ Pune, India
}

\begin{abstract}
Synthetic polymers are widely researched for their use in tissue engineering. Control in size, surface area, pore size, and elasticity are the biggest advantages of using a man-made polymer. However, often the polymers are hydrophobic (do not encourage cell attachment); hence, it is hugely challenging to integrate them with the normal tissues. Herein, we have tried to overcome this disadvantage of polymers by coating them with citrate-stabilized gold nanoparticles and arginine. High-density polyethylene, upon multiple treatments, shows low water contact angle, which encourages cell attachment and proliferation in comparison to the untreated polymers.
\end{abstract}

Keywords: tissue engineering, gold nanoparticle, HDPE hydrophilicity

\section{Introduction}

High-density polyethylene (HDPE) is a great choice for the preparation of variety of materials due to its facile malleability and strength. It is hard and also non-biodegradable, which enable it to maintain its location after suturing. Furthermore, generation of interconnected microsized pores in HDPE is also relatively easy. For these reasons, HDPE has widely been harnessed in making artificial limbs, ${ }^{1}$ organs for tissue engineering purpose. Unfortunately, HDPE's hydrophobic nature (coming from the inherent $-\mathrm{CH}_{2}$ - backbones) discourages cell adhesion, resulting in poor integration with the healthy tissues. Keeping aside the immunological challenges, the initial hurdle of mismatch between the foreign body and live tissues is crucial and needs attention for further research. Herein, we propose to "hydrophilize" the HDPE surface by sequential plasma treatment, citrate-stabilized gold nanoparticle (AuNP) attachment, ${ }^{2-4}$ followed by treating them with the amino acid "arginine". Layer-bylayer assembly (Figure 1) of AuNPs and arginine is expected to transform the porous HDPE surface hydrophilic from a hydrophobic one, without compromising with the inherent useful properties of HDPE.

\section{Materials and methods Reagents and chemicals}

HDPE was a generous donation from a Mumbai-based company "Biopore Surgicals". Arginine and fetal bovine serum were obtained from Sigma-Aldrich. Citric acid was obtained from Merck and used as such. Chloroauric acid was purchased from Sisco Research Laboratories. 3-(4,5-Dimethylthiazoyl-2-yl)-2,5-diphenyltetrazolium bromide (MTT) dye was procured from Invitrogen. Dulbecco's Modified Eagle's Medium was supplied by Hi-Media. PSN 100× (penicillin, streptomycin, neomycin
Correspondence: Bhagavatula LV Prasad Physical Chemistry Division, CSIRNational Chemical Laboratory, Dr Homi Bhaba Road, Pune 4I I008, India

Tel +9l $20259020 \mid 3$

$\mathrm{Fax}+912025902636$

Email pl.bhagavatula@ncl.res.in 
A

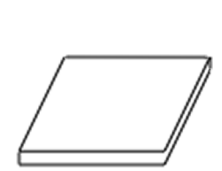

a. Untreated HDPE scaffolds

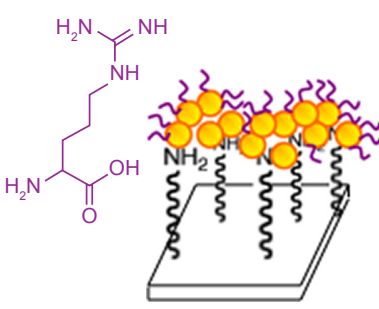

d. Lysine coated on AuNPs (deposited on HDPE scaffolds)

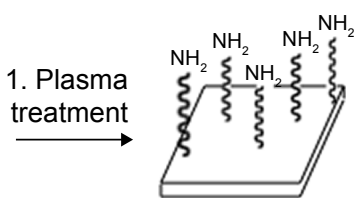

b. Plasma treated scaffolds
2. Incubation with AuNP 1d

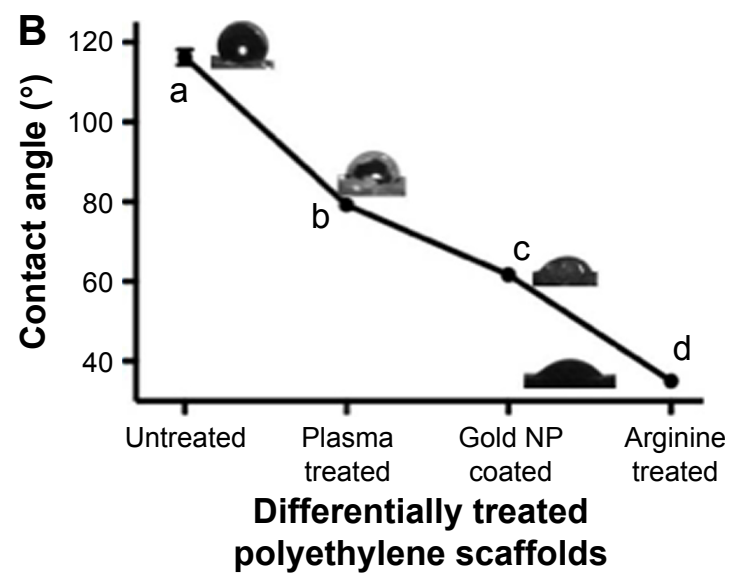

Figure I (A) I. $\mathrm{N}_{2}: \mathrm{H}_{2}$ ammonia plasma (power 80, time $20 \mathrm{~min}$ ) was used to functionalize polyethylene surface. 2. Citrate-stabilized AuNPs (0.I mM sol) were deposited on the treated scaffolds by electrostatic attractions. 3. Finally, the scaffolds were incubated overnight in $4 \mathrm{~g} / \mathrm{L}$ water solution. (B) Water contact angles (using $10 \mu \mathrm{l}$ of water) were measured on different scaffolds [a-d].

Abbreviations: AuNPs, gold nanoparticles; d, day; min, minutes; HDPE, high-density polyethylene.

antibiotic cocktail) and trypsin ethylenediaminetetraacetic acid mixture were purchased from Gibco Life Technologies. Water used in the benchtop chemical reactions was of milli-q grade. HeLa cells (passage no 15/16) were purchased from the animal cell repository of NCCS (National Centre For Cell Sciences), Pune, India.

\section{Synthesis of AuNPs}

In a typical synthesis, AuNPs were synthesized by the reduction of chloroauric acid ( $0.1 \mathrm{mM}$ solution) by citric acid. Fifty milliliters of $\mathrm{HAuCl}_{4}(0.1 \mathrm{mM})$ was refluxed, $500 \mathrm{mg}$ of citric acid was added to it, and the solution was continued to reflux for $10 \mathrm{~min}$. AuNPs formed with the development of a ruby red color with a peak in the optical absorbance spectra (Jasco V-570 ultraviolet-visible/near infrared spectrophotometer) at $520 \mathrm{~nm}$. Transmission electron microscopy (FEI, TECNAI G2 TF 20) analysis indicated the particle size to be around $15-20 \mathrm{~nm}$.

\section{Plasma treatment of HDPE scaffolds}

The scaffolds were treated with ammonia plasma $\left(\mathrm{H}_{2}: \mathrm{N}_{2}\right.$ ratio 3:2) under $80 \mathrm{~W}$ power setting for $20 \mathrm{~min}$ in Emitech Plasma Asher (K1050X). ${ }^{3}$

\section{Layer-by-layer assembly of AuNP and arginine}

After plasma treatment, the scaffolds were immediately dipped in $0.1 \mathrm{mM}$ gold sol and stirred for 1 day, which resulted in AuNP attachment. ${ }^{3}$ The time was optimized by solid-state ultraviolet spectrophotometry (Jasco V-570 ultraviolet-visible/near infrared/NIR Spectrophotometer). Finally, the scaffolds were incubated overnight in $4 \mathrm{~g} / \mathrm{L}$ arginine in milli-q water solution. The extent of hydrophilicity was determined by contact angle measurement (GBX model DIGIDROP contact angle instrument, Windrop software).

\section{Cell proliferation (MTT) assay}

Polymer scaffolds under different treatments were cut into pieces of $1 \mathrm{~cm}^{2}$ and placed aseptically into a 24-well cell culture plate. They were sterilized with ultraviolet exposure for $40 \mathrm{~min}$ under cell culture hood. HeLa cells (10,000 cells $/ 500 \mu \mathrm{L}$ of complete medium) were seeded on each scaffold and allowed to proliferate for $48 \mathrm{~h}$ at $37^{\circ} \mathrm{C}$ in $5 \% \mathrm{CO}_{2}$ atmosphere. Ten microliters of MTT $(5 \mathrm{mg} / \mathrm{mL})$ reagent in phosphate-buffered saline (PBS) was added to each well and reincubated for another $3 \mathrm{~h}$ at $37^{\circ} \mathrm{C}$. Formazan crystals were made soluble by adding $200 \mu \mathrm{L}$ of dimethyl sulfoxide to each well. After $10 \mathrm{~min}$, the absorbance of the purple color was read at $570 \mathrm{~nm}$. The $\%$ mitochondrial activity was calculated as (A570 of treated samples/A570 of untreated samples) $\times 100$, where $A$ is the absorbance. Data shown are mean \pm standard error of $n=3$. Cell counting experiment was performed according to a similar protocol.

\section{Scanning electron microscopic (SEM) images of cells grown on different scaffolds}

HeLa cells were incubated with differently treated scaffolds as described in the previous section. Ultraviolet-visible/near 


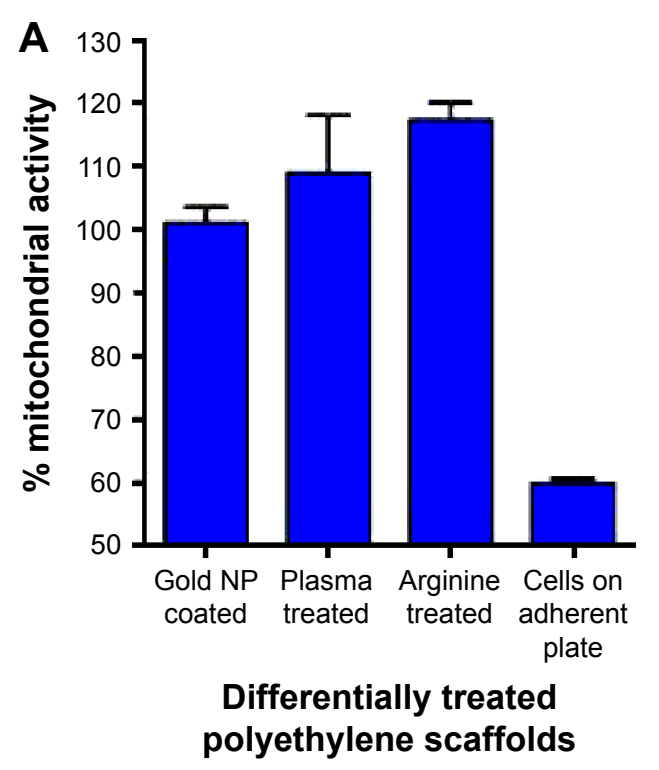

\section{B}

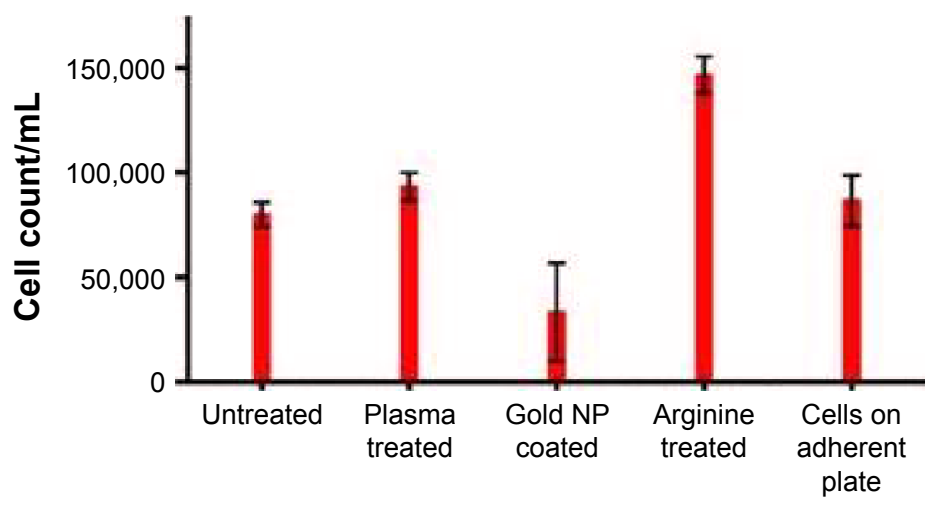

Differentially treated polyethylene scaffolds

Figure 2 Effect of different scaffolds on cellular proliferation: (A) MTT assay and (B) cell counting experiment. Abbreviations: MTT, 3-(4,5-dimethylthiazoyl-2-yl)-2,5-diphenyltetrazolium bromide; NP, nanoparticle.

infrared scaffolds were removed from culture condition, washed 2x with PBS, fixed with 4\% PFA (paraformaldehyde). They were exposed to gold sputtering (for SEM) and directly taken into SEM instrument.

\section{Results and discussion}

The general strategy adopted to convert hydrophobic HDPE surface to a hydrophilic one is depicted in Figure 1A. After each treatment (plasma, AuNP, and arginine), the scaffolds showed gradually lowered contact angle (Figure 1B), where a huge shift from $110^{\circ}$ to $33^{\circ}$ at an ambient condition suggests hydrophilic properties induced by the differential layer by layer procedure followed here. Apart from that, infrared and solid-state nuclear magnetic resonance spectra (data not shown here) confirm the attachment of arginine molecules on the citrate-capped AuNP. According to the in vitro experiments (MTT and cell counting, Figure 2A and B), arginine-coated scaffolds show significantly increased live cell population. We hypothesize, this is due to the fact that adhering cells found a strong support to hold on to and "spread" thereafter. Arginine, due to its guanidinium group's lone electrons (Figure 1A), imparts delocalized positive charge, which makes the scaffolds hydrophilic. On the other hand, the cellular membranes are the self-assembly of amphiphilic lipidic units where the negatively charged phosphate groups are exposed to the outside. We summarize that the resulting electrostatic attraction between the cellular membrane and the treated HDPE surface helps in proper anchorage. The polyethylene scaffolds having the right porosity and interconnection allow the flow of nutrients (media) in an optimal way to help in proliferation of cells - almost mimicking the in vivo situation. SEM images (Figure 3) show the cells grown on the treated scaffold to be healthier and they were clearly seen to form pili in order to attach to the solid surface. Surprisingly, in vitro results also show that only plasma-treated scaffolds have high degree of cellular attachment. But with plasma treatment, the scaffold lost its hydrophilicity with time (around 8 days), while the fully treated scaffolds (plasma, AuNP, arginine) retained their hydrophilicity for a very long period. The choice of nanoparticle was also unique. AuNP is nontoxic and possesses easier surface chemistry in comparison to other nanomaterials. Moreover, attachment of AuNPs (15-20 nm diameter) increases the surface area by a few folds, which ultimately increases the chance of cell adherence.

\section{Conclusion}

The arginine-treated scaffolds proved to be a permanent solution to the problem of hydrophobicity of the polymers. For a long period ( 2 months), the scaffolds did not lose their hydrophilicity (proven by contact angle, data not shown). Moreover, being a nondegradable and hard solid, it has the potential to be stable as an implant. Apart from HDPE, different polymers (eg, poly-L-lactic acid, poly-lactic-co-glycolic acid) have been widely researched as a material to be used for tissue engineering purpose. This platform technique (plasma treatment, AuNP, and arginine layer-by-layer assembly) is equally applicable on any polymeric material. On the other 

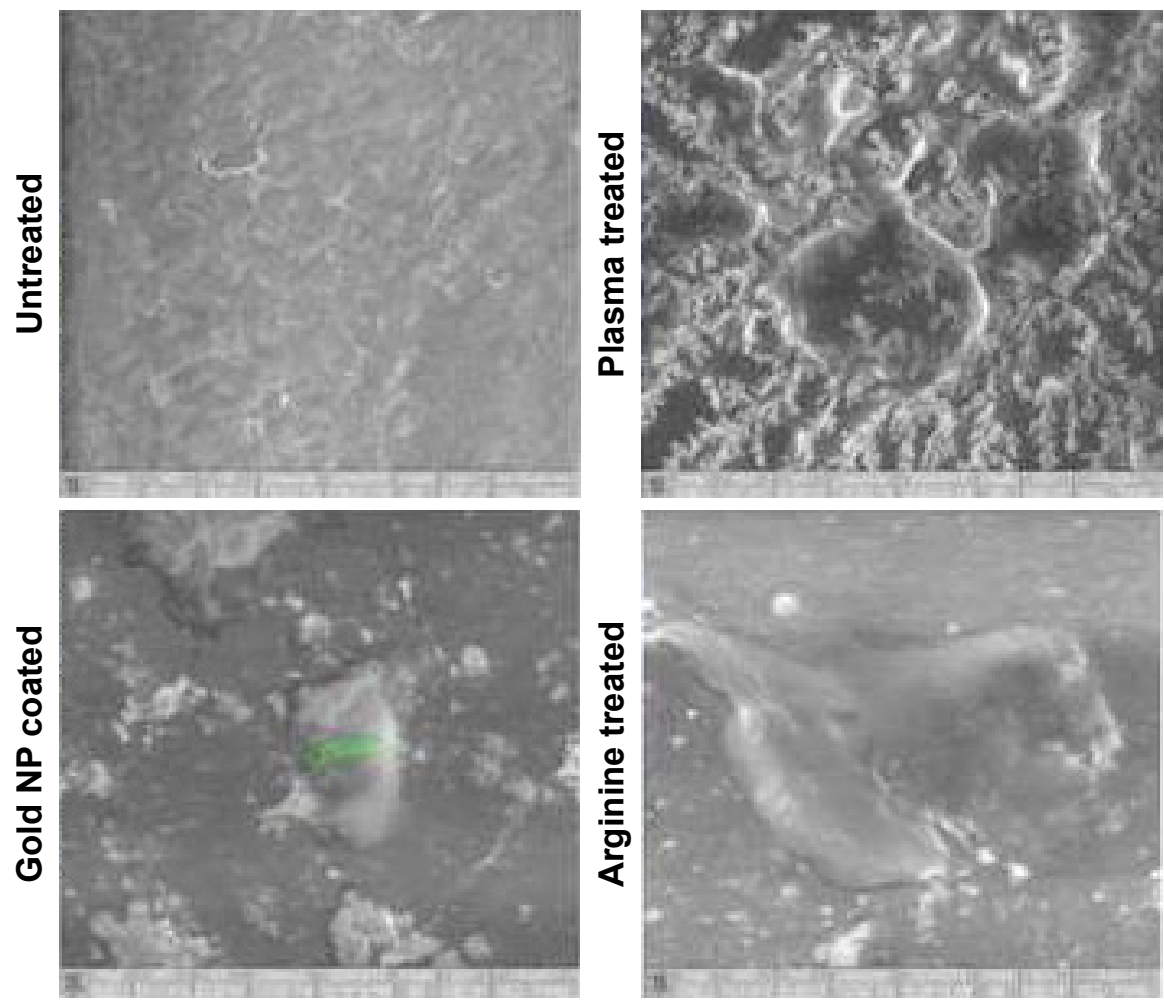

Figure 3 SEM images of cells grown on different scaffolds.

Abbreviations: NP, nanoparticle; SEM, scanning electron microscopy.

hand, arginine (especially R9) is a well-established transfection agent which encourages cell entry when tagged to a moiety of interest (like siRNA). These properties have been well harnessed in this work, and it opens up many new routes to challenge similar problems.

\section{Acknowledgments}

The authors sincerely acknowledge Dr. Vinay Agrawal (Biopore Surgicals) and Dr. V Premnath for polyethylene scaffolds. Poulomi Sengupta thanks CSIR-SRF for fellowship and DST WOS-A grant number SR/WOS-A/ CS-94/2012 for fellowship and consumables. Sachin Surwase thanks "CSIR-Molecules to Materials to Devices" project for project assistantship. The authors thank CSIR-National Chemical Laboratory for providing lab facilities.

\section{Disclosure}

The authors report no conflicts of interest in this work.

\section{References}

1. Leong KF, Cheah CM, Chua CK. Solid freeform fabrication of threedimensional scaffolds for engineering replacement tissues and organs. Biomaterials. 2003;24(13):2363-2378.

2. D'Britto V, Tiwari S, Purohit V, et al. Composites of plasma treated poly (etherimide) films with gold nanoparticles and lysine through layer by layer assembly: a "friendly-rough" surface for cell adhesion and proliferation for tissue engineering applications. J Mater Chem. 2009; 19(4):544-550.

3. D'Britto, V. Synthesis of metal nanoparticles and polymer/metal nanoparticle composites: investigation towards biological applications. $\mathrm{PhD}$ Thesis. CSIR-National Chemical Laboratory, Pune, India, 2010.

4. D'Britto V, Kapse H, Babrekar H, et al. Silver nanoparticle studded porous polyethylene scaffolds: bacteria struggle to grow on them while mammalian cells thrive. Nanoscale. 2011;3(7):2957-2963.

\section{Publish your work in this journal}

The International Journal of Nanomedicine is an international, peerreviewed journal focusing on the application of nanotechnology in diagnostics, therapeutics, and drug delivery systems throughout the biomedical field. This journal is indexed on PubMed Central, MedLine, CAS, SciSearch ${ }^{\circledR}$, Current Contents ${ }^{\circledR} /$ Clinical Medicine,

\section{Dovepress}

Journal Citation Reports/Science Edition, EMBase, Scopus and the Elsevier Bibliographic databases. The manuscript management system is completely online and includes a very quick and fair peer-review system, which is all easy to use. Visit http://www.dovepress.com/ testimonials.php to read real quotes from published authors. 